\title{
Rancangan Penghatar Hasil Rontokan Padi Pada Mesin Combine Harverter
}

\author{
${ }^{1)}$ Ahmad Hanafie, ${ }^{2)}$ Andi Haslindah, ${ }^{3)}$ Saripuddin $M,{ }^{4)}$ Awaluddin Yunus \\ ${ }^{1,2}$ Dosen Program Studi Teknik Industri Universitas Islam Makassar \\ ${ }^{3)}$ Dosen Program Studi Mesin Universitas Islam Islam Makassar \\ ${ }^{4)}$ Dosen Program Studi Agribisnis Universitas Islam Islam Makassar \\ Jl. Perintis Kemerdekaan KM 9 no 29, tlp 0411 588-167 Makassar \\ Email: ahmadhanafie.dty@uim-makassar.ac.id
}

\begin{abstract}
ABSTRAK, Mesin combine harverter yang dirancang secara terintegrasi dalam pengolahan hasil panen. Adalah pengambungan mesin thresher yaitu mesin yang merontokkan padi secara statis yang artinya mesin dalam posisi diam, bahan yang datang ke mesin untuk proses perontokan, lalu hasil rontokan tersebut dipindahkan pada mesin pembersih untuk memisahkan butiran padi yang hampa serta batang, daun atau kotoran lain yang masih menempel pada butiran padi sedangkan combine harveter adalah mesin yang digerakkan secara dinamis yang mampu digerakkan secara vertikal hasil rontokan ini dibawak kebagian mesin pembersih menghilangkan dedaunan serta batang yang masih terikut pada butiran padi, dalam penelitian kedua mesin digabung menjadi satu manfaat untuk mengurangi waktu kerja serta efesiensi biaya. Bak penghantar padi yang telah dirangkai dengan komponen lainnya ukuran panjang $180 \mathrm{~cm}$. Lebar $14 \mathrm{~cm}$ dengan ketebalan 0,5 $\mathrm{mm}$. Model bak penghantar ini dibuat secara terpisah-pisah, bak teridi dari 4 bagian yaitu bak bagian bawah (landasan penghantar), bagian bagian atas (penutup), Pentup bak kontrol bagian bawah untuk pengontrol bagian perontokan dan, bak kontrol bagian atas untuk bagian mesin thresher. penutup bak penghantar terdiri 2 bak yang terletak pada ujung bawah atas, dan pada bagian atas bawah. Fungsi penutup bak pengantar adalah sebagai alat kontrol bila mana terjadi suatu hal pada bagian antara ruang perontokan dengan arah ke penghantar, biasa terjadi bila butiran padi dan batang padi yang terbawah saat diroktokkan. Begitu juga alat kontrol pada bagian atas fungsi sama sebagai pengontrol antara penghantar ke bagian thresher.
\end{abstract}

\section{Kata kunci: Rancangan, Bak Penghantar}

\section{PENDAHULUAN}

\subsection{Latar Belakang Penelitian}

Dalam proses produksi terjadinya proses input lalu menuju ke proses sehingga menjadi suatu produk atau hasil.

Proses produksi adalah suatu kegiatan yang mengkombinasikan faktor-faktor produksi (man, money, material, method) yang ada untuk menghasilkan suatu produk, baik berupa barang atau jasa yang dapat diambil nilai lebihnya atau manfaatnya oleh konsumen. Sifat proses produksi adalah mengolah, yaitu mengolah bahan baku dan bahan pembantu secara manual dengan menggunakan peralatan, sehingga menghasilkan suatu produk yang nilainya lebih dari barang semula.

Pada mesin combine harverter yang dirancang secara terintegrasi dalam pengolahan hasil panen. Adalah pengambungan mesin thresher yaitu mesin yang merontokkan padi secara statis yang artinya mesin dalam posisi diam, bahan yang datang ke mesin untuk proses perontokan, lalu hasil rontokan tersebut dipindahkan pada mesin pembersih untuk memisahkan butiran padi yang hampa serta batang, daun atau kotoran lain yang masih menempel pada butiran padi sedangkan combine harveter adalah mesin yang digerakkan secara dinamis yang mampu digerakkan secara vertikal hasil rontokan ini dibawak kebagian mesin pembersih menghilangkan dedaunan serta batang yang masih terikut pada butiran padi, dalam penelitian kedua mesin digabung menjadi satu manfaat untuk mengurangi waktu kerja serta efesiensi biaya.

Olehnya itu dalam penelitian ini bagaimana merancang alat penghantar untuk mentransformasi hasil rontokan padi yang masih tercampur dengan butiran padi dengan daun dan batang untuk 
diproses lebih lanjut ke bagian perbersih atau thresher. Dalam rancangan penghantar ini bagiamana merancang suatu alat penghantar yang optimal yang mampu membawah kebagian thresher pada mesin combine harverter.

\subsection{Rumusan Penelitian}

Berdasarkang latar belakang masalah dalam penelitian, maka rumusan penelitian adalah bagaimanan merancang bak sistem penghantar yang mampu menghantar butiran padi dari area perontokan ke bagian thresher.

\subsection{Tujuan Penelitian}

Adapun tujuan penelitian ini adalah untuk merancang merancang bak sistem penghantar yang mampu menghantar butiran padi dari area perontokan ke bagian thresher.

\section{METODE PENELITIAN}

\subsection{Tempat Dan Waktu Penelitian}

Pelaksanaan Penelitian ini bertempat lokasi pada bagian produksi CV. Candue Nutindo, di Jl. Salo Kabupaten Pinrang pada penelitian ini dilakukan pada perancangan Bak Penghantar merupakan bagian dari Mesin Combine Harverter.

Waktu pelaksanaan penelitian atau pengambilan data Tanggal, 3 April 2018 Sampai dengan 4 April 2018.

\subsection{Langkah-langkah Pengambilan Data}

Langkah penelitian pengambilan data adalah caraa yang dapat digunakan untuk pengumpulan data. Data dalam penelitian ini adalah data primer yang bersumber dari secara langsung. Untuk memperoleh data penelitian jenis ini digunakan tiga jenis metode yaitu:

1. Data pada perusahaan yaitu pengumpulan data hasil pengukuran material

2. Wawancara yaitu dengan pengumpulan data tanya jawab pihak perusahaan yanga menangani langsung pekerjaan tersebut yaitu pada bagian produksi serta wawancara dengan pihak yang terkait langsung dengan penelitian dilapangan

3. Observasi dan Pengamatan dilakukan langsung pada objek penelitian

Merupakan data yang diperoleh melalui studi dan literature yang mendukung penelitian ini.

\section{HASIL DAN ANALISA}

\subsection{Analisa Material}

Penggunaan material dalam perancangan bak perlu diperhatikan karena material yang diangkut adalah gabah, namun kita tidak bisa mengangap remeh sekicil-kecilnya butoran padi namun mampu mengikis secara perlahan terhadap material yang digunakan. Olehanya itu plat yang digunakan dengan ketabalan $0,5 \mathrm{~mm}$.

Kerja pelat adalah suatu proses membuat benda kerja dari lempengan pelat yang dibentuk sedemikian juga agar dapat membentuk suatu benda yang dapat digunakan. Dalam melakukan praktik kerja kita harus mengetahui urutan langkah-langkah kerja sebagai berikut.

1. Pembuatan gambar kerja.

2. Melakukan pemotongan pelat.

3. Menghitung besarnya bending (penekukan).

4. Melakukan penekukan.

1. Assembling

2. Finished work (pengamplasan.

Besi siku adalah besi plat yang bentuknya siku atau memiliki sudut 90 derajat. Panjang besi siku ini biasanya adalah 6 meter. Ukuran besi suku bervariasi $2 \mathrm{~cm}, 3 \mathrm{~cm}, 4 \mathrm{~cm}$, dan, $5 \mathrm{~cm}$.

Puli dapat digunakan untuk mentransmisikan daya dari poros satu ke poros yang lain melalui sistem transmisi penggerak berupa flat belt, V-belt atau circular belt.

Baut dan mur merupakan alat pengikat yang sangat penting dalam mencegah kecelakaan atau kerusakan pada mesin. Pada setiap alat dan mesin yang dibuat dengan cara mengkombinasikan beberapa bagian (komponen), perananbaut dan mur sangat dibutuhkan untuk menyatukan konponen-komponen tersebut.Baut dan mur terbagi dalam beberapa macam sesuai dengan kegunaanya masing-masing. 
Poros adalah sebuah berbentuk silinder pejal yang berfungsi sebagai tempat duduknya elemen elemen lai seperti pulley, sprocket, roda gigi dan kopling dan juga berperan sebagai elemn penerus daya dan putaran dari mesin penggerak.

Adapun ukuran dimensi bak yang akan digunakan terlihat pada tabel sebagai berikut:

Tabel 1. Ukuran Bagian-Bagian Bak Penghantar

\begin{tabular}{|l|c|l|l|}
\hline \multicolumn{1}{|c|}{ Uraian } & $\begin{array}{c}\text { Quantit } \\
\text { y }\end{array}$ & \multicolumn{1}{|c|}{ Ukuran } & Jenis Bahan \\
\hline Penutup Bak Penghantar & 1 & $180 \times 14 \times 0.1$ & Besi plat \\
\hline $\begin{array}{l}\text { Plat Penahan Penutup Bak } \\
\text { Penghantar }\end{array}$ & 2 & $190 \times 3 \times 0,1$ & Besi strip \\
\hline Bagian Bawah Bak Penghantar & 1 & $180 \times 14 \times 0.1$ & Besi plat \\
\hline Penahan Penutup & 1 & $100 \times 4 \times 4$ & Besi siku 40 ks \\
\hline Penutup Bak Pengontrol & 2 & $38 \times 14 \times 0,1$ & Besi plat \\
\hline Stant Pintu & 1 & $100 \times 4 \times 4$ & Besi siku 40 ks \\
\hline Rantal Pengerak & 2 & $360 \mathrm{~cm}$ & Besi \\
\hline Plat Penahan Penghantar & 7 & $5 \times 12 \times 0,1$ & Besi plat \\
\hline Bagian Penghantar & 7 & $20 \times 12 \times 0,1$ & Karet \\
\hline $\begin{array}{l}\text { Bearing Duduk As Inch } \\
\text { Pillow Block }\end{array}$ & 4 & 1 inchi & Besi \\
\hline Besi As & 2 & 1 inchi & Besi \\
\hline Sekrup dan baut & 16 & $5 \mathrm{~cm}$ & Besi \\
\hline Pully & 1 & & Steel pully \\
\hline V-Bell & 1 & & karet \\
\hline Skematik Sprocket & 2 & & Besi \\
\hline Besi Rantai & 1 & $360 \mathrm{~cm}$ & Besi \\
\hline
\end{tabular}

\subsection{Perancangan Bak Penghantar}

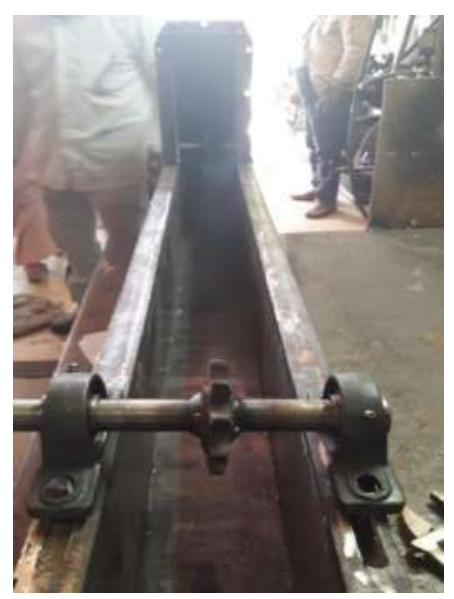

Gambar 1. Rangka Bak Penghantar Padi

Gambar 1. Menunjukkan rangka bak penghantar padi yang telah dirangkai dengan komponen lainnya ukuran panjang $180 \mathrm{~cm}$. Lebar $14 \mathrm{~cm}$. Model bak penghantar ini dibuat secara terpisah-pisah, bak teridi dari 4 bagian yaitu bak bagian bawah (landasan penghantar), bagian bagian atas (penutup), Pentup bak kontrol bagian bawah untuk pengontrol bagian perontokan dan, bak kontrol bagian atas untuk bagian mesin thresher 


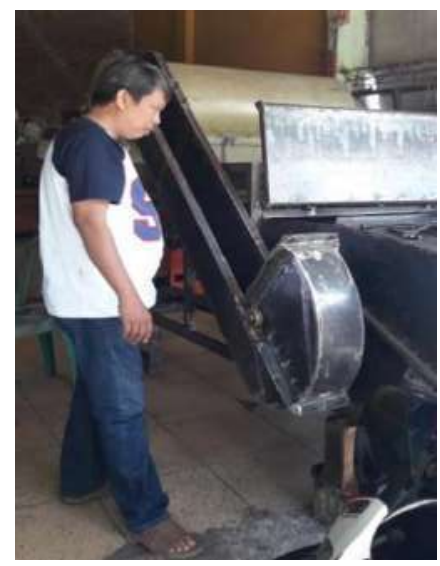

Gambar 2. Pemasangan Rak Penghantar

Gambar 2. Menunjukkan bak penghantar di rangkai dengan bagian bawah adalah bagian perontok sedangkan diatas adalah bagian thresher. Bak ini dirancang mampu di buka secara terpisah-pisah bila terjadi bottle neck maka akan dibuka bagian dimana terjadi kemacetan.

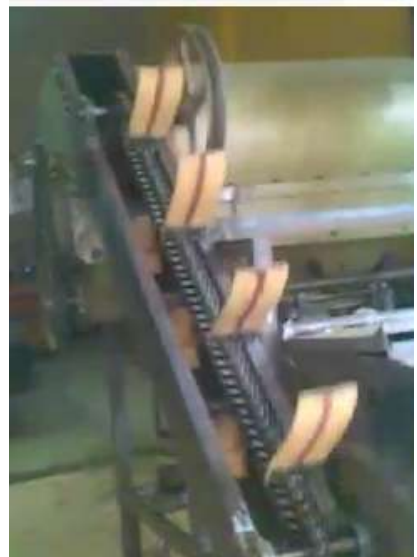

\section{Gambar 3. Penghantar Padi}

Gambar 3. Menunjukkan penghantar padi, bagian penghantar padi terdiri dari tujuh yang dipasang pada bagian penahan, fungsi alat ini bila digerakkan maka secara beraturan bergerak kerah atas sambil membawah material butoran padi lalu di transper ke bagian pembersih atau thresher. Kecepatan penghantar dapat disesuaikan dengan jumlah material yang diterima pada bagian perontokan.

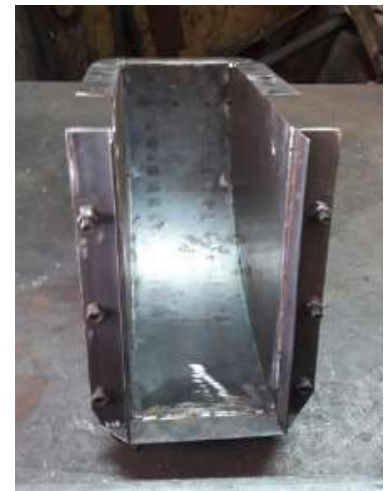

\section{Gambar 4. Penutup Bak Penghantar}

Gambar 4 menunjukkan penutup bak penghantar terdiri 2 bak yang terletak pada ujung bawah atas seperti telihat pada gambar 2, dan pada bagian atas bawah seperti terlihat pada gambar 5. Fungsi penutup bak pengantar adalah sebagai alat kontrol bila mana terjadi suatu hal pada bagian antara ruang perontokan dengan arah ke penghantar, biasa terjadi bila butiran padi dan 
batang padi yang terbawah saat diroktokkan. Begitu juga alat kontrol pada bagian atas fungsi sama sebagai pengontrol antara penghantar ke bagian thresher.

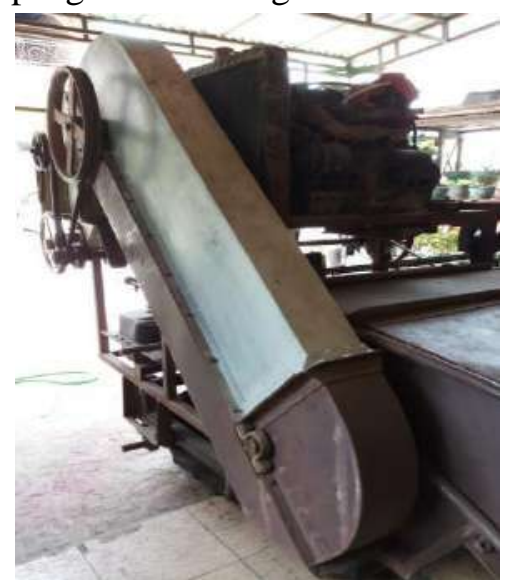

Gambar 5. Bak Penghantar

Gambar 5. Menunjukkan bak pengjantar yang utuh rancangan ini dibuat secara terpisahpisah bagian bawah adalah pengontrol bak, sedangkang pada bagian tengah atau penutup bila ada penghantar yang akan diganti karetnya. Alat bak penghantar padi sangat dinamis digunakan.

\section{PEMBAHASAN}

Pada mesin combine harverter yang dirancang secara terintegrasi dalam pengolahan hasil panen. Adalah pengambungan mesin thresher yaitu mesin yang merontokkan padi secara statis yang artinya mesin dalam posisi diam, bahan yang datang ke mesin untuk proses perontokan, lalu hasil rontokan tersebut dipindahkan pada mesin pembersih untuk memisahkan butiran padi yang hampa serta batang, daun atau kotoran lain yang masih menempel pada butiran padi sedangkan combine harveter adalah mesin yang digerakkan secara dinamis yang mampu digerakkan secara vertikal hasil rontokan ini dibawak kebagian mesin pembersih menghilangkan dedaunan serta batang yang masih terbawah pada butiran padi, dalam penelitian kedua mesin digabung menjadi satu manfaat untuk mengurangi waktu kerja serta efesiensi biaya. Olehnya itu dalam penelitian ini bagaimana merancang alat penghantar untuk mentransformasi hasil rontokan padi yang masih tercampur dengan butiran padi dengan daun dan batang untuk diproses lebih lanjut ke bagian perbersih atau thresher.

\section{PENUTUP}

Bak penghantar padi yang telah dirangkai dengan komponen lainnya ukuran panjang 180 $\mathrm{cm}$. Lebar $14 \mathrm{~cm}$ dengan ketebalan 0,5 mm. Model bak penghantar ini dibuat secara terpisahpisah, bak teridi dari 4 bagian yaitu bak bagian bawah (landasan penghantar), bagian bagian atas (penutup), Pentup bak kontrol bagian bawah untuk pengontrol bagian perontokan dan, bak kontrol bagian atas untuk bagian mesin thresher. penutup bak penghantar terdiri 2 bak yang terletak pada ujung bawah, dan pada bagian atas bawah. Fungsi penutup bak pengantar adalah sebagai alat kontrol bila mana terjadi suatu hal pada bagian antara ruang perontokan dengan arah ke penghantar, biasa terjadi bila butiran padi dan batang padi yang terbawah saat diroktokkan. Begitu juga alat kontrol pada bagian atas fungsi sama sebagai pengontrol antara penghantar ke bagian thresher.

Penghantar padi, bagian penghantar padi terdiri dari tujuh yang dipasang pada bagian penahan, fungsi alat ini bila digerakkan maka secara beraturan bergerak kerah atas sambil membawah material butoran padi lalu di transper ke bagian pembersih atau thresher. Kecepatan penghantar dapat disesuaikan dengan jumlah material yang diterima pada bagian perontokan.

\section{DAFTAR PUSTAKA}


Ahmad Hanafie (2007), Modifikasi Helm Standar Kendaraan Roda Dua Yang Ergonomis Bagi Penguna Telpon Seluler, Jurnal Iltek, Vol. II, Nomor 4, April 2007, Hal 313-319, Fakultas Teknik Univ. Islam Makassar.

Ahmad Hanafie, Darmulia (2014), Pengembangan Mesin Perontok Padi (Combine Harverter) yang Ergonomis Untuk Meningkatkan Produksi, Prosiding Seminar Nasional Teknologi Industri II Atim 2014, ISSN. 978-602-14822-16, Hal. 346-381.

Ahmad Hanafie, A.Haslindah, Muh. Fadhli (2015), Pengembangan Mesin Perontok Padi (Combine Harverter) yang Ergonomis Untuk Meningkatkan Produksi, Majalah Teknik Industri, Vol. 22/No.1/Juni 2015, ISSN. 1410-7015, Hal. 67-72.

Ahmad Hanafie, A.Haslindah, Muh. Fadhli (2015), Pengembangan Mesin Perontok Padi (Combine Harverter) yang Ergonomis Untuk Meningkatkan Produksi, Prosiding Seminar Nasional Tahunan Teknik Mesin Indonesia-XIV, Banjarmasing, 7-8 Oktober 2015.

Astika (2007), Ergonomi Pertumbuhan Dan Peranannya Dalam Pembangunan, http://www.baliheag.org

Eko Nurmianto (2007), Ergonomi, konsep dasar \& aplikasinya, Penerbit Guna Widya, Jakarta.

Iftikar Z. Sutalaksana; Ruhana A; John H. T (2006), Analisa dan Perancangan Sistem Kerja. Jurusan TI ITB.

Muh. Yani Syafei Dr,H.,ST.,MT, (2007), Aplikasi Konsep Ergonomi Dalam Pengembangan Design Produk Akan Memberikan Nilai Jual Produk yang Tinggi dan dan Keunggulan Bersaing. Seminar Nasional Ergonomics in product Development.

Noor Fitrihana, (2007), Memperbaiki Kondisi Kerja di Industri Garmen, Ergonomi Kerja, B4D3 Consultants, hal 1- 12.

Karl T. Ulrich, Steven D. Eppinger (2001), Perancangan dan Pengembangan Produk, Mc Graw Hill

Roche; Davila, USA (1972), Dalam bukunya Wignjosoebroto, Sritomo Sritomo (2000), Ergonomi, Studi Gerak \& waktu. Penerbit Guna widya, Jakarta.

Saripuddin M, Ahmad Hanafie, Suradi (2017), Effect of Welding on Strength, and Hardness on Combine Harverter Machine Design, Prosiding International Conference on Industrial Technology for Sustainable Development (ICon-ITSD) 25-26 Oktober

Saripuddin M, Suradi, Ahmad Hanafie (2018) Analysis of Cutting Speed On Surface Roughness Relationship Through St-90 Material Lathe Use Chisel Carbide, Proceding $1^{\text {st }}$ International Conference on Material Engineering and Managemen UNIFA, 1-2 Agustus 2018

Sritomo Wignjosoebroto, (2008), Ergonomi, Studi Gerak \& waktu. Penerbit Guna widya, Jakarta.

Sritomo Wignjosoebroto, Srigunani, Ahmad Hanafie. (2003), Modifikasi mesin perontok Padi yang Ergonomis. PEI, Yogyakarta.

Sudjana (1989), Metoda Statistika, penerbit Tarsito, Bandung.

Usulan Perbaikan Sistem Kerja yang Lebih Ergonomis pada Stasiun Kerja Perakitan dan Pemolesan di PT. YPTI, Jun 15th, 2007 by admin.

Diskusi:

- Apa faktor yang dipertimbangkan dalam penelitian ini?

- Bagaimana hasil dari studi kelayakan yang dilakukan? 